\title{
PERFORMANCE EVALUATION OF NANO GRAPHITE INCLUSIONS IN CUTTING FLUIDS WITH MQL TECHNIQUE IN TURNING OF AISI 1040 STEEL
}

\author{
M M S Prasad ${ }^{1}$, R.R.Srikant ${ }^{2}$ \\ ${ }^{I}$ Professor, Dept of Mechanical Engg, Regency Institute of Technology, Yanam-U T of Puducherry, India \\ ${ }^{2}$ Associate Prof, Dept of Mechanical Engg, GIT, GITAM University, Visakhapatnam, A.P., India \\ prasadmms@yahoo.co.in,r.r.srikant@gmail.com
}

\begin{abstract}
Liberation of heat and generation of friction associated with any machining operation ever pose a problem which not only reduce the tool life but also impair quality of the product. Cutting fluids have been the conventional choice to curtail friction and temperatures in machining because of its lubrication and cooling actions. However, considering health hazards posed by the conventional cutting fluids to health of the workers and ecology, the quest is towards identifying alternative strategies to the usual flood application. Selection and use of proper lubricant that can improve the overall cutting phenomena which is an important aspect in reducing the cutting forces and temperatures The present work studies the use of nano cutting fluids in MQL which is a minimal cutting fluid technique, for turning operation using HSS and cemented carbide tools. Development of nano materials by nanotechnology technique, dispersing them in the cutting fluid improve the effectiveness of the cutting fluid and hence nano graphite powder is selected of particle size $80 \mathrm{~nm}$ in varying proportions i.e. 0.0\%, 0.1\%, 0.3\% and 0.5\% by weight are mixed in water soluble oil and applied drop by drop. Experimentation is carried out at different flow rates like $5 \mathrm{ml} / \mathrm{min} 10 \mathrm{ml} / \mathrm{min}$ and $15 \mathrm{ml} / \mathrm{min}$ with nanoparticle suspended fluids along with dry machining, flood coolant machining under constant cutting conditions. Experimental results are very encouraging with much reduction in surface roughness, tool flank wear, temperatures and cutting forces is observed in fluids with nanoparticle inclusions. Different properties of the nanofluids are estimated through a series of standard tests.
\end{abstract}

Keywords: Machining, nano Graphite, minimum quantity lubrication, cutting fluids.

\section{INTRODUCTION}

Machining is one of the major manufacturing processes and is often accomplished by very high energy consumed to shear off the material by the cutting tool. Due to this, abnormal amount of friction and in turn very high temperatures are generated at the tool, work and chip interfaces. Inadvertently, the machining parameters like cutting force, tool wear and surface roughness are to be increased [1]. In order to reduce the these parameters, cutting fluids are the best choice as they provide cooling and lubrication to the cutting zone [2,3]. However, cutting fluids introduce major health and safety concerns, high handling and carrying costs, disposal, water and soil pollution, $[4,5]$ exposure to cutting fluids for long term causes dermatitis [6] . It was estimated by the National Institute for Occupational Safety and Health (NIOSH) that in every year 1.2 million workers involved in machining, forming and other metal working operations are exposed to metal working fluids [7]. It was reported recycling services for the cutting fluids in the United States charge twice the purchasing price for disposal and the cost is four times as much in Europe [8]. This has prompted the search for alternative methods, wherein the use of cutting fluids is minimized.

Minimum Quantity Lubrication (MQL) is one such strategy where very minimal amounts of the fluids are used. Nevertheless, to achieve high cooling ability with minimum quantity lubrication, a fluid with high thermal conductivity of the fluids, like nanofluids, must be chosen [9-11].

\section{LITERATURE REVIEW}

Cutting fluids are said to be accounting to major expenditure in any metal cutting industry, in fact more than the cost of the cutting tools [12]. Considering the stringent environmental laws, high cost of the cutting fluids, ecological and issues related to health hazards, various methods are evolved to minimize or eliminate the usage of the cutting fluids [13]. This has lead to the development of minimum quantity lubrication (MQL) [14]. MQL has been applied in several operations like turning, milling and grinding and encouraging results were obtained [14-16]. However, since the amount of fluid supplied is very low, a fluid with superior properties, compared to the 
conventional fluids is required. In this context, nanofluids are emerging as possible solutions. In the preparation of nanofluid, the choice of nano particle is critical and depends on the application. Since, in the present application lubrication and cooling are required, solid lubricants may be chosen.

$\mathrm{CaF}_{2}$ is reported to significantly reduce coefficient of friction [17] and tool flank wear [18]. By using cemented carbide tool in the presence of solid lubricant, turning was carried out on EN 8 steel work piece and lubricating properties were assessed based on the measurement of the cutting forces [19]. Improved surface quality of the bearing steel with mixed ceramic tools was reported when $\mathrm{MoS}_{2}$ and graphite were used [20]. Graphite, due to its structure has a distinct place in the class of solid lubricants and is very widely used in machining. Park et. al [21] have studied the use of graphene based nanofluid as lubricant for ball milling operation and have reported good results for $0.1 \%$ inclusion levels. However, graphene is costly compared to graphite.

In the present work, AISI 1040 steel was machined with HSS and Cemented carbide tools. Nanofluids made up of nano graphite powder particles ( $80 \mathrm{~nm}$ size ) in various proportions like $0 \%, 0.1 \%, 0.3 \%$ and $0.5 \%$ by weight and water soluble oil as base fluid are used as coolants in MQL. The fluids were first characterized and then different flow rates of $5 \mathrm{ml} / \mathrm{min}, 10$ $\mathrm{ml} / \mathrm{min}$ and $15 \mathrm{ml} / \mathrm{min}$ flow rates are tried in MQL in addition to both dry machining \& flood coolant machining. The effect on various process parameters like surface finish, cutting forces, tool wear and temperatures was studied.

\section{EXPERIMENTATION}

\subsection{Lubricant Mixture Properties}

The nanofluids was prepared by sonicating the previously functionalized Nanoparticles using a sonicator. Functionalisation is done to make the Nanoparticles hydrophilic from hydrophobic. Initially, use of surfactant TritonX-100 was opted, however, it was found to decrease the thermal conductivity of the fluid (Table.1), hence, functionalization was chosen. Nano graphite material was calcinated by heating in furnace whose temperature is maintained at $450^{\circ} \mathrm{C}$ for about $45 \mathrm{~min}$ and then refluxed by using 6 molar concentric $\mathrm{H} 2 \mathrm{SO} 4$ with $\mathrm{HNO}_{3}$ in the ratio of $2: 1$ for 6 hours. After cooling the mixture, it was washed with water and by using vacuum filtration, it is completely filtered to drain off water. This process was repeated to attain till $\mathrm{pH}$ value of 7 (neutral) is obtained. In order to get functionalized nano graphite powder, the slurry is dried in oven at $80^{\circ} \mathrm{C}$ in vacuum for $16 \mathrm{hrs}$. After sonication, the fluids were used for experimentation. The supply flow is controlled by a regulating valve provided in the set up. The fluids were tested to evaluate the properties like density, thermal conductivity, kinematic viscosity, $\mathrm{pH}$.

\subsection{Machining Tests}

In order to test the effectiveness of the fluids in machining, the fluids were supplied at different flow rates as lubricant. The experimental set-up is shown Fig 1 and the details are presented in Table 2. A separate set up has been made to store, carry and supply of the solid lubricant mixture to the cutting zone.

The variables which effect the machining performance like tool geometry, cutting conditions, type of the lubricant, HSS and uncoated cemented carbide tools were selected based on the manufacturers recommendations. All the cutting tests are performed on PSG 124 lathe under constant cutting conditions. Cutting forces are measured by using 4 component piezo electric KISTLER dynamometer (Type-9272). Talysurf is employed to measure the surface roughness (Ra). By using metallurgical microscope, tool wear is measured off line at the end of each cut under $5 \mathrm{X}, 10 \mathrm{X}$ magnifications. $\mathrm{K}$ type thermocouple is used to measure the cutting temperatures placed below the tool insert in case of carbide tool and connected to the tool in case of HSS tool. All the experiments were conducted in triplicate and the average of the values has been considered.

\section{RESULTS AND DISCUSSIONS}

\subsection{Properties of the Nano Graphite Lubricant}

\section{Mixture}

Density values measured are given in table-3 for different volume proportions of nano cutting fluids. Density has a detrimental effect on the heat transfer coefficient in convection. The kinematic viscosity of nano particle suspended cutting fluids is given in table- 4 and it is found that there is an increase in viscosity with increase in weight percentage of the nano particles. As viscosity is an important property for lubricants, apparently, cutting fluids with higher concentration of nano graphite can serve as better lubricants. Further, decrease in viscosity is observed as temperature increased. It may be noted that the overall combined effect of both these parameters is critical in deciding the lubricating properties of the fluids.

Apart from lubrication, cooling is another prime objective of cutting fluid. Thermal conductivity of the fluids is estimated at different temperatures as given in Table-5. Results indicate rise in thermal conductivity with increase in inclusion levels. Unlike most liquids, which show a fall in thermal conductivity with rise in temperature, the fluids show a consistent increase in the thermal conductivity with temperature. This property may be inherited from water, which is a major constituent of the fluids. Since thermal conductivity is found to rise with increase in content of inclusion, fluids with higher inclusion levels content can apparently be used for machining that produces higher temperatures. 
The resistance of the fluids to microbial action is affected to a large extent by the $\mathrm{pH}$ value of the fluid. $\mathrm{pH}$ values the different fluids are given in table-6. The results showed rise in $\mathrm{pH}$ value with inclusion level, which is characterized by rise in alkalinity of the fluid. $\mathrm{pH}$ values too high or low can prove hazardous to the operator and pose a problem in waste disposal.

\subsection{Machining Parameters}

\subsubsection{Cutting Forces}

To appraise the lubricating properties of the fluids, cutting forces were measured while machining in all the considered conditions of lubrication. Variation of the cutting force with machining time for Nanofluids at different flow rates are presented in Figs. 2-7 for both Cemented Carbide and HSS tools. Dry cutting has given rise to highest cutting forces followed by the soluble oil (flood cooling). It can be seen that increase in inclusion of the fluid has decrease in cutting force. The possible reason may be the effectiveness of the solid lubricant at nano level size and also the trends observed for the kinematic viscosities. Also the forces decreased with increase in the flow rate of the fluid.

When experiment results under $15 \mathrm{ml} / \mathrm{min}$ flow rate compared with $5 \mathrm{ml} / \mathrm{min}$ flow rate using HSS tool, the reduction in cutting forces was found $65 \%$ in plain MQL, $69 \%$ in MQL with $0.1 \mathrm{wt} \%$ graphite, $67 \%$ in MQL with $0.3 \mathrm{wt} \%$ graphite and $69 \%$ in MQL with $0.5 \mathrm{wt} \%$ graphite nano fluid. Similarly, using with cemented carbide insert, the reduction was found $6 \%$ in plain MQL, $5 \%$ in MQL with $0.1 \mathrm{wt} \%$ graphite, $5 \%$ in MQL with $0.3 \mathrm{wt} \%$ graphite and $15 \%$ in MQL with $0.5 \mathrm{wt} \%$ graphite nano fluid.

From the above findings, the resultant force measurements corresponding to MQL with $0.5 \mathrm{wt} \%$ graphite nano fluid were less than the measurements with all other experimental combinations under $15 \mathrm{ml} / \mathrm{min}$ flow rate except in case of MQL with $0.3 \mathrm{wt} \%$ graphite nano fluid and machined with HSS ( with a marginal difference of $2 \%$ more than $0.5 \mathrm{wt} \%$ ) superior that means, as weight percentage increased from $0.0 \%$ to $0.5 \%$ the nano graphite particle suspended fluid behaved like pure base oil which means the role of nano particle at chip tool interface was being nullified result in level of resultant force required against nano particle was reduced. This lead to reduction in magnitude of cutting forces. This will be attributed to reduction of cutting zone temperatures result in less friction and decrease in BUE formation.

However, from the results, when compared to HSS tool, the cutting forces appeared to be less in Cemented carbide insert in the prevailing cutting conditions.

\subsubsection{Cutting Temperature}

Since measurement of the temperatures at tip is difficult, an embedded thermocouple method is adopted to estimate the effectiveness of the fluids in cooling. The measured temperatures correspond to a nodal point located at some distance to the cutting tip. Since the present study aims to compare the performance of the cutting fluids and is not interested in estimation of actual cutting temperature, this strategy has been followed. A standard $\mathrm{K}$ type thermocouple is used to monitor the temperature by using a digital temperature indicator. Results shown in Fig 8 to 13 indicate that in dry machining cutting temperatures are highest for dry machining, while soluble oil (flood cooling) produces least temperatures. For increase in the percentage inclusion of the cutting fluids and the flow rates, the temperatures decreased. It may be noted that similar trend was observed in thermal conductivity measurements.

When experiment results under $15 \mathrm{ml} / \mathrm{min}$ flow rate compared with $5 \mathrm{ml} / \mathrm{min}$ flow rate using HSS tool, the reduction in cutting temperature was found $26 \%$ in plain MQL, $24 \%$ in MQL with $0.1 \mathrm{wt} \%$ graphite, $30 \%$ in MQL with $0.3 \mathrm{wt} \%$ graphite and $27 \%$ in MQL with $0.5 \mathrm{wt} \%$ graphite nano fluid. Similarly, using with cemented carbide insert, the reduction was found $15 \%$ in plain MQL, $12 \%$ in MQL with $0.1 \mathrm{wt} \%$ graphite, $16 \%$ in MQL with $0.3 \mathrm{wt} \%$ graphite and $20 \%$ in MQL with $0.5 \mathrm{wt} \%$ graphite nano fluid as nano size graphite particles more or less suspended completely in the base fluid without any agglomeration thereby reduce friction at the toolchip interface can be expected. Another reason would be reduced cutting forces which in turn lowered the power consumption during machining operation. Whatever power that was consumed converted to heat of less quantity distributed along primary zone ie shear zone and secondary zone i.e. tool-chip interface.

From all above findings, the reduction in cutting temperature was maximum in MQL with $0.3 \mathrm{wt} \%$ graphite nano fluid under $15 \mathrm{ml} / \mathrm{min}$ flow rate when machined with HSS tool and maximum in MQL with $0.5 \mathrm{wt} \%$ graphite nano fluid under same flow rate. However it was found only a marginal difference of $3 \%$ to $4 \%$ less than MQL with $0.3 \mathrm{wt} \%$ graphite nano fluid in case of machined with cemented carbide insert. However, from the results, when compared to HSS tool, the cutting temperatures appeared to be less in Cemented carbide insert in the prevailing cutting conditions.

\subsubsection{Surface Roughness}

Surface roughness plays an important role on product quality. In this study, surface roughness was measured by Talysurf. Results shown in the fig. 14 \& 15. Dry lubrication gives maximum surface roughness while flood cooling gives the minimum surface finish. In nano cutting fluids, percentage inclusion of graphite decreases the surface roughness. The 
possible reasons may be due to the decrease in cutting forces and temperatures at higher inclusions.

When experiment results under $15 \mathrm{ml} / \mathrm{min}$ flow rate compared with $5 \mathrm{ml} / \mathrm{min}$ flow rate using HSS tool, the reduction in surface roughness was found $3.1 \%$ in plain MQL, $2.6 \%$ in MQL with $0.1 \mathrm{wt} \%$ graphite, $1.6 \%$ in MQL with $0.3 \mathrm{wt} \%$ graphite and $1.1 \%$ in MQL with $0.5 \mathrm{wt} \%$ graphite nano fluid. Similarly, using with cemented carbide insert, the reduction was found $3.4 \%$ in plain MQL, 5.2\% in MQL with $0.1 \mathrm{wt} \%$ graphite, $2.7 \%$ in MQL with $0.3 \mathrm{wt} \%$ graphite and $1.5 \%$ in MQL with $0.5 \mathrm{wt} \%$ graphite nano fluid.

From all above findings, the reduction in surface roughness was maximum in MQL with $0.3 \mathrm{wt} \%$ graphite nano fluid under $15 \mathrm{ml} / \mathrm{min}$ flow rate in both HSS and cemented carbide tool machining which gave improved finish obtained on work piece material depending on controlling the deterioration of auxiliary cutting edge of abrasion, chipping and BUE formation. It was further observed reduction in surface roughness with $0.3 \mathrm{wt} \%$ graphite nano fluid due to exhibiting enhanced thermal and lubricating properties of nano fluids like high thermal conductivity, dynamic viscosity and heat transfer coefficient that reduced frictional forces at chip tool interface and tool work interface result in decrease in temperature at the cutting zone thereby decrease in tool wear and hence improvement in surface finish.

However, from the results, when compared to HSS tool, the surface roughness appeared to be less in Cemented carbide insert in the prevailing cutting conditions.

\subsubsection{Tool Flank Wear}

Tool wear is a major parameter that characterizes the efficiency of machining process. In the present work tool wear is measured periodically. Tool wear results are shown in fig 16 to 21. Similar to surface roughness, values of tool wear obtained in MQL happen to fall in between dry and flood lubrications. Increase in percentage inclusion of graphite and flow rate decreased the tool wear. This is because of the better cooling and lubricating properties at those conditions. The trend of result is comparable with the results reported in literature [21].

When experiment results under $15 \mathrm{ml} / \mathrm{min}$ flow rate compared with $5 \mathrm{ml} / \mathrm{min}$ flow rate using HSS tool, the reduction in tool wear was found $9 \%$ in plain MQL, $9 \%$ in MQL with $0.1 \mathrm{wt} \%$ graphite, $12 \%$ in MQL with $0.3 \mathrm{wt} \%$ graphite and $11 \%$ in MQL with $0.5 \mathrm{wt} \%$ graphite nano fluid. Similarly, using with cemented carbide insert, the reduction was found $9 \%$ in plain MQL, $7 \%$ in MQL with $0.1 \mathrm{wt} \%$ graphite, $11 \%$ in MQL with $0.3 \mathrm{wt} \%$ graphite and $10.8 \%$ in MQL with $0.5 \mathrm{wt} \%$ graphite nano fluid.
At high and moderate cutting speeds, under plain MQL, the coolant may not have enough time to remove the accumulated heat at cutting zone result in less reduction of temperature that leads to more predominant formation of BUE and increase in tool wear. However, under MQL with graphite nano fluids machining which help in reduce the temperature result in a decrease in formation of BUE due to enhanced thermo physical properties of nano fluids.

In any machining operation, primary deformation zone and secondary deformation zone where heat generation is more and induces very high cutting temperatures. At these temperatures, the solid graphite lubricant generates thin lubricating film in tool work piece leading to reduction of tool wear. Further, low shear resistance, sliding action and low coefficient of friction with in the contact interface reduce the flank wear. The combined effect leads to decrease in tool flank wear at MQL with $0.3 \mathrm{wt} \%$ graphite particle nano fluids under $15 \mathrm{ml} / \mathrm{min}$ flow rate.

However, from the results, when compared to HSS tool, the tool wear appeared to be less in Cemented carbide insert in the prevailing cutting conditions.

\section{CONCLUSIONS}

The effectiveness of the Nanofluids in MQL has been studied in this paper through a series of tests. The following conclusions may be drawn from the present work:

1. Nano fluids have demonstrated consistently better performance in MQL compared to dry machining. Though flood lubrication is shown to perform better, the disadvantages associated with it, outweigh its performance.

2. Increase in percentage inclusion of the nano graphite leads to better performance of the fluids in terms of properties and machining responses like cutting forces, temperatures, surface roughness and tool wear.

3. Higher flow rates have shown better performance. However, too high flow rates will come out of MQL and the disadvantages of flood lubrication like microbial contamination and disposal problems will prevail. Also the costs of Nanofluids has to be taken into consideration while deciding the flow rate.

4. At the present stage of experimentation, $0.3 \%$ nano graphite particle inclusions at $15 \mathrm{ml} / \mathrm{min}$ flow rate can be taken as the best combination. However, other tests like microbial contamination and biodegradability need to be done before arriving at a final conclusion.

\section{REFERENCES}

[1]. Byers, J P Metal working fluids, first edition, 1994 (CRC, USA).

[2]. Milton C Shaw, Metal cutting principles, $2^{\text {nd }}$ edition, Oxford University Press, USA, 2004. 
[3]. Herry P Byers, Metal working fluids, $1^{\text {st }}$ edition, CRC, USA, 1994.

[4]. T D Howes, H K Toenshoff, W Heuer, Environmental aspects of grinding fluids, Annal of CIRP (College International Pour La Recherche En Productique), 40 (2) 1991, 623-629.

[5]. G Byrne, E Scholta, Environmentally clean machining processes-a strategic approach, Annals of CIRP, (College International Pour La Recherche En Productique), 42(1) 1993, 471-474.

[6]. Bennet E O Dermatitis in the metal working industry, Special Publication SP-11, Society of tribologists and lubrication Engineers, part Ridge, IL (1992), pp.31 to 36.

[7]. National Institute for Occupational Safety and Health (NIOSH). Criteria for a Recommended StandardOccupational Exposure to Metal working Fluids, January 1998.

[8]. L B Abhang and M Hameedullah, Experimental investigation of minimum quantity lubricants in alloy steel turning, International Journal o engineering Science and Technology, 2(7),2010, 3045-3053.

[9]. V Vasu, K Rama Krishna, A C S Kumar, Analytical prediction of thermo physical properties of fluids embedded with nanostructured materials, International Journal of Nanoparticles, 1(1), (2008) pp.32-49.

[10]. A R Moghadassi, S M Hosseini, D Henneke, A Elkamek, A model of nanofluid effective thermal conductivity based on dimensionless groups, Journal of Thermal Analysis and Calorimetry 96 (1) (2009) 81-84.

[11]. V Vasu, K R Krishna and A C S Kumar, Exploitation of Thermal Properties of Fluids Embedded with Nanostructured materials, International Energy Journal, 8(3), (2007), 178186.

[12]. Klocke, F.,Eisenblatter, G., Dry cutting, Annals of CIRP (College International Pour La Recherche En Productique), 46(2), (1997), 519-525.

[13]. Khan M M A, Dhar N R, Performance evaluation of Minimum Quantity Lubrication by vegetable oil in terms of cutting force, cutting zone temperature, tool wear, job dimension and surface finish in turning AISI-1060 steel, Journal of Zhejiang University SCIENCE A 2006 7(11):1790-1799.

[14]. A S Varadarajan, P K Philip, B Ramamoorthy, Investigation on hard turning with minimal cutting fluid application and its comparison with dry and wet turning, International journal of Machine Tools and Manufacture 42(23) 2002, 193-200.

[15]. S Shaji, V Radhakrishnan, An investigation of surface grinding using graphite as lubricant, International Journal of Machine tools and manufacture, 42(6)(2002) 733-740.

[16]. Shen B Shih, A J Tung S C and Hunter, M. Application of nanofluids in minimum quantity lubrication grinding Tribology Trans. 51(6), (2008), 730-737.

[17]. D Jianhuya, C Tongkun, Y Xuefeng, L Jianhuua, Self lubrication of sintered ceramic tool with CAF2 additions in dry cutting, International Journal of Machine Tools and Manufacture (2005) 1-7.

[18]. G S Lathkar, U S K Bas, Clean metal cutting process using solid lubricant, Proceedings of the $19^{\text {th }}$ All India Manufacturing Technology Design and Research (AIMTDR) Conference, Narosa Publishing house, IIT Madras, 2000, pp, 15-31.

[19]. P Vamsi Krishna, D Nageswara Rao, Performance evaluation of solid lubricants in terms of machining parameters in turning, International Journal of Machine tools \& Manufacture 48 (2008) 1131-1137.

[20]. N Suresh Kumar Reddy, P V Rao, Experimental Investigation to study the effect of solid lubricants on cutting forces and surface quality in end milling, International journal of Machine Tools and Manufacture 46 (2006)189- 198.

[21]. Kyung-Hee Park, Brent Ewald and Patrick Y. Kwon, Effect of Nano-Enhanced Lubricant in Minimum Quantity Lubrication Balling Milling, Journal of Tribology, Transactions of ASME, 133 (2011), 031803-1 to 8.

Table-1: Thermal conductivity measurement

\begin{tabular}{|l|c|c|}
\hline & $\begin{array}{c}\text { Thermal Conductivity, } \mathbf{k} \\
(\mathbf{W} / \mathbf{m K})\end{array}$ & $\begin{array}{c}\text { \% increase in thermal } \\
\text { conductivity w.r.t Base } \\
\text { fluid }\end{array}$ \\
\hline Soluble oil oil with & $\mathbf{0 . 5 5 5}$ & $\mathbf{4 . 5 1}$ \\
\hline $\begin{array}{l}\text { Soluble oil } \\
\text { functionalized nanographite } \\
\text { (Sample A) }\end{array}$ & $\mathbf{0 . 5 8}$ & $\mathbf{- 3 . 4 2}$ \\
\hline $\begin{array}{l}\text { Soluble oil with nanographite } \\
\text { and Triton X-100 } \\
\text { (Sample D) }\end{array}$ & $\mathbf{0 . 5 3 6}$ & \\
\hline
\end{tabular}


Table 2: Experimental conditions in machining

\section{Machine Tool:}

- Lathe machine: PSG company, Coimbatore, India

- Speed range: 63-1250 rpm

- Motor capacity: 10 h.p.

- Cutting tool (insert): Carbide, CNMG 120408(H-13A, ISO specification)

- Tool holder: PSRNR $12125 \mathrm{f09}$ (ISO specification)

- Work specimen : AISI 1040 steel ( $\mathrm{C}=0.36-0.45 \%, \mathrm{Mn}=0.6-1 \%, \mathrm{Si}=0.2-0.3 \%, \mathrm{~S}=0.025 \%$ \& $\mathrm{P}=0.015 \%$ )

- Size: $50 \emptyset \times 400 \mathrm{~mm}$

- Hardness: $30 \pm 2 \mathrm{HRC}$, heat treated.

\section{Process Parameters:}

- Cutting speed: $105 \mathrm{~m} / \mathrm{min}$

- Feed: $0.14 \mathrm{~mm} / \mathrm{rev}$

- Depth of cut: $1 \mathrm{~mm}$

- Environment: Solid lubricant (Graphite)

- Lubricating oil: soluble oil

- Solid lubricant particle size: $<80 \mathrm{~nm}$

- Flow rate of the lubricant: $10 \mathrm{ml} / \mathrm{min}$

\section{Cutting Tool Geometry:}

- Back rake angle:

- Side rake angle:

- End cutting edge angle:

- Side cutting edge angle:

- End Relief Angle:

- Side Relief angle:

- Nose radius:

$\begin{array}{ll} & 0^{0} \\ 5^{0} & \\ 10^{0} & \\ 10^{0} & \\ & \\ 50^{0} & \\ 0.5 \mathrm{~mm} & \end{array}$

\section{Sonicator}

- Maximum power output: 600 watts

- Operating frequency: $20 \mathrm{kHz}$

- Input:110 V AC@10 A

- Programmable timer: $1 \mathrm{~s}-1 \mathrm{~h}$

\section{Thermocouple:}

- Designation: K type, shielded thermocouple

- Element size: $2 \mathrm{~mm}$ O D (d) x 20 mm long (L)

- Element type: Duplex

- Sheath material: Recrystalized Alumina

- Temperature range: $-250^{\circ} \mathrm{C}$ to $1260^{\circ} \mathrm{C}$

- Tolerance: $\pm 2.2^{\circ} \mathrm{C}$ or $\pm 0.75 \%$ (whichever is greater between $0-1250^{\circ} \mathrm{C}$ )

\section{Lathe Tool Dynamometer:}

- Make: kistler instrument co, west Germany.

- Model : 9272

- Measuring range: up to $10 \mathrm{KN}$

- Type: piezo electric Dynamometer

\section{Tally Surf:}

- Stylus material: Diamond

- Stylus radius: $0.0025 \mathrm{~mm}$

- Cut-off length: 0.8x5

- Accuracy: $3 \%$ of reading 
Table-3: Density of nanofluids

\begin{tabular}{|c|c|}
\hline Density $\left(\mathbf{g r} / \mathbf{c m}^{\mathbf{3}}\right)$ & $\begin{array}{c}\text { Measured Density of nanofluid } \\
\left(\mathbf{g} / \mathbf{c m}^{\mathbf{3}}\right)\end{array}$ \\
\hline Wt \% & 0.99 \\
\hline 0 & 0.990 \\
\hline 0.1 & 0.991 \\
\hline 0.3 & 0.992 \\
\hline 0.5 & \\
\hline
\end{tabular}

Table-4: Kinematic viscosity of nanofluids

\begin{tabular}{|l|l|l|l|l|}
\hline \multicolumn{6}{|l|}{ Kinematic Viscosity ( stokes) } \\
\hline Temp $($ C) & Soluble oil & 0.1\% wt gr & 0.3\% wt gr & 0.5\% wt gr \\
& & & & \\
\hline 25 & 0.018 & 0.021 & 0.026 & 0.032 \\
\hline 30 & 0.015 & 0.019 & 0.024 & 0.028 \\
\hline 35 & 0.013 & 0.017 & 0.021 & 0.025 \\
\hline 40 & 0.011 & 0.016 & 0.018 & 0.022 \\
\hline 45 & 0.009 & 0.015 & 0.017 & 0.021 \\
\hline 50 & 0.008 & 0.014 & 0.015 & 0.020 \\
\hline 55 & 0.008 & 0.014 & 0.015 & 0.019 \\
\hline 60 & 0.007 & 0.013 & 0.015 & 0.019 \\
\hline
\end{tabular}

Table-5: Thermal conductivity of nanofluids

\begin{tabular}{|c|c|c|c|c|}
\hline \multicolumn{5}{|c|}{ Thermal conductivity (W/m K) } \\
\hline $\operatorname{Temp}\left({ }^{\circ} \mathrm{C}\right)$ & $\begin{array}{l}\text { Soluble } \\
\text { oil }\end{array}$ & $\begin{array}{l}\text { 0.1wt \% } \\
\text { Gr }\end{array}$ & $\begin{array}{l}0.3 \text { wt } \% \\
\text { Gr }\end{array}$ & $\begin{array}{l}0.5 \text { wt \% } \\
\text { Gr. }\end{array}$ \\
\hline 25 & 0.550 & 0.574 & 0.584 & 0.599 \\
\hline 30 & 0.555 & 0.580 & 0.590 & 0.609 \\
\hline 35 & 0.560 & 0.584 & 0.594 & 0.613 \\
\hline 40 & 0.565 & 0.589 & 0.599 & 0.618 \\
\hline 45 & 0.570 & 0.594 & 0.604 & 0.623 \\
\hline 50 & 0.575 & 0.599 & 0.609 & 0.628 \\
\hline 55 & 0.580 & 0.604 & 0.614 & 0.633 \\
\hline 60 & 0.585 & 0.609 & 0.619 & 0.638 \\
\hline 65 & 0.590 & 0.614 & 0.624 & 0.643 \\
\hline 70 & 0.595 & 0.619 & 0.629 & 0.648 \\
\hline
\end{tabular}


Table-6

\begin{tabular}{|l|l|}
\hline pH: \\
\hline Gr Wt \% & pH \\
\hline 0 & 8.03 \\
\hline 0.1 & 7.99 \\
\hline 0.3 & 7.95 \\
\hline 0.5 & 7.73 \\
\hline
\end{tabular}

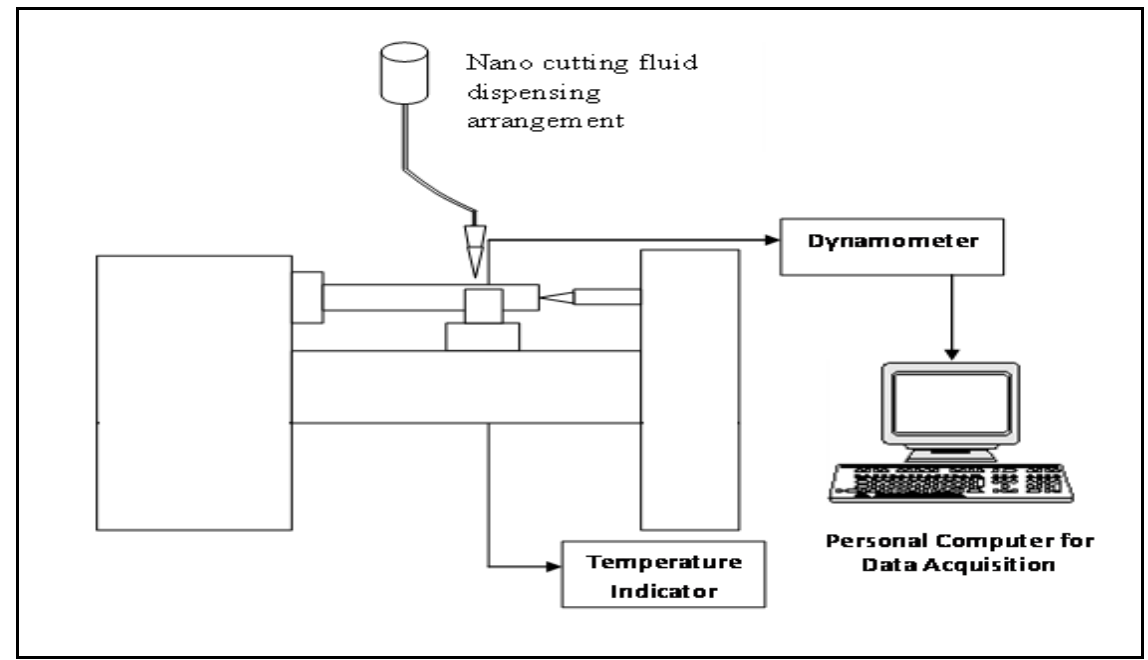

Fig. 1 Schematic representation of experimental set-up

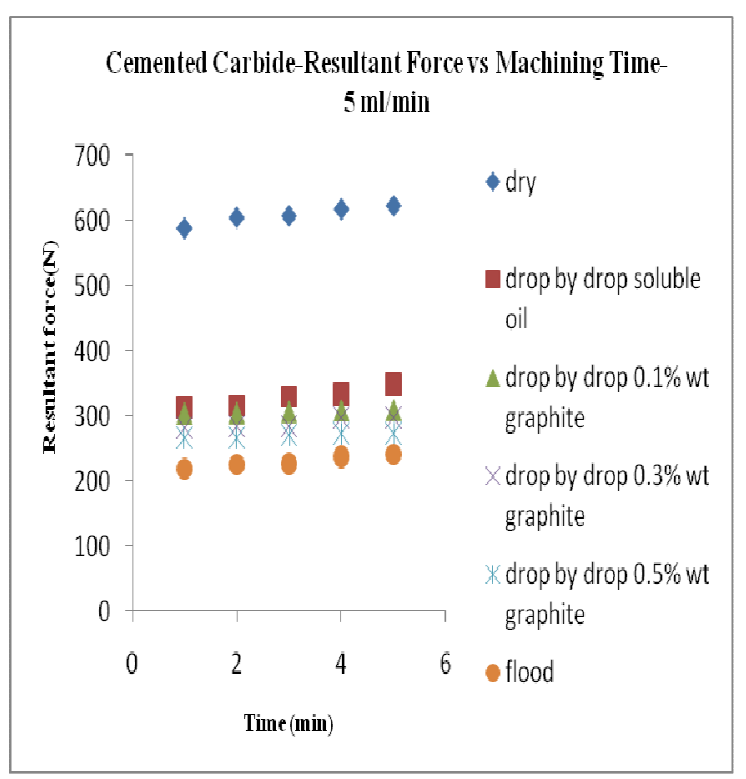

Fig.2 Variation of resultant force with machining time when used Cemented Carbide tool at $5 \mathrm{ml} / \mathrm{min}$

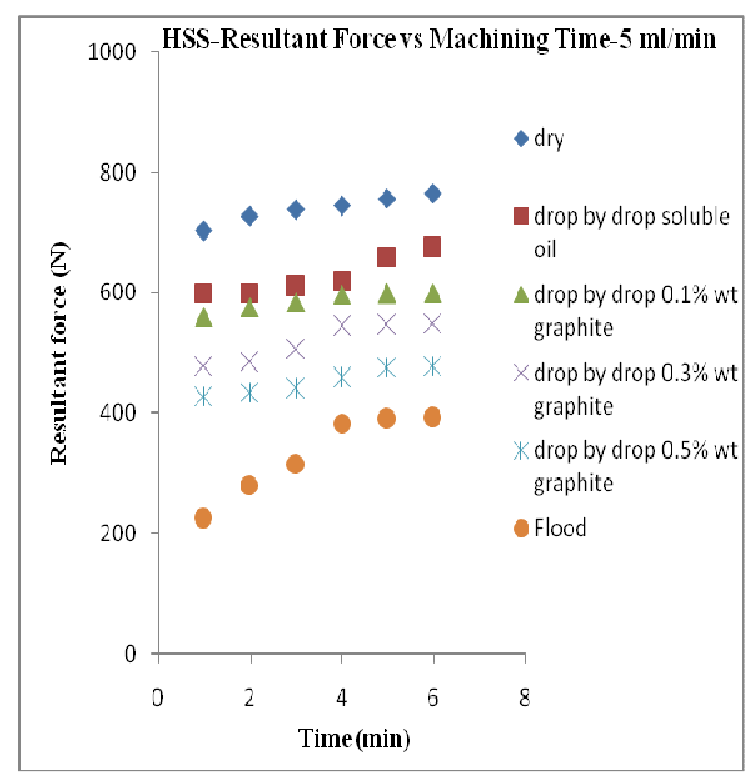

Fig.3 Variation of resultant force with machining time when used HSS at $5 \mathrm{ml} / \mathrm{min}$ 


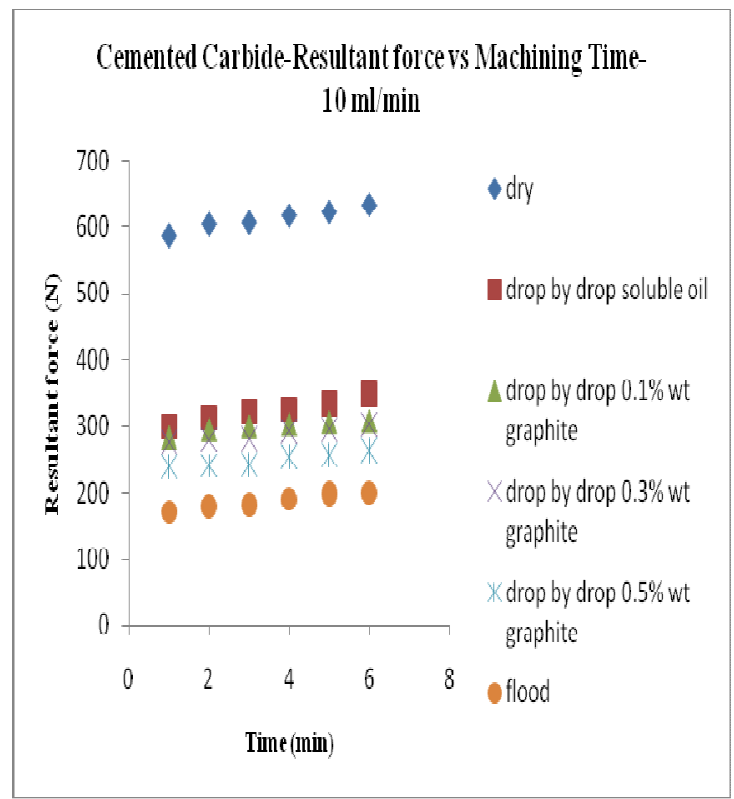

Fig.4 Variation of resultant force with machining time when used Cemented Carbide tool at $10 \mathrm{ml} / \mathrm{min}$

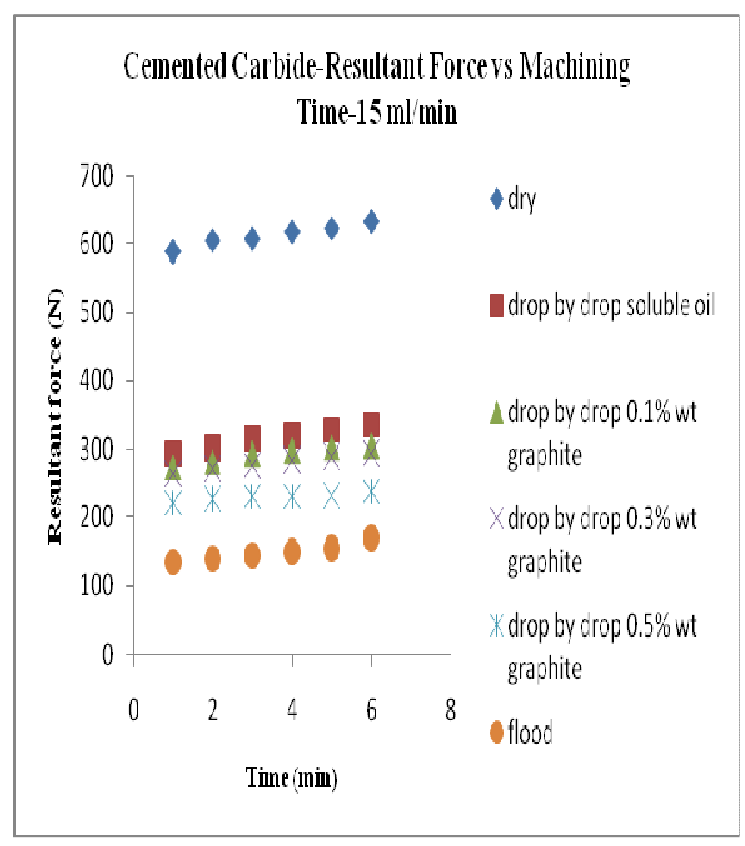

Fig.6 Variation of resultant force with machining time when used Cemented Carbide tool at $15 \mathrm{ml} / \mathrm{min}$

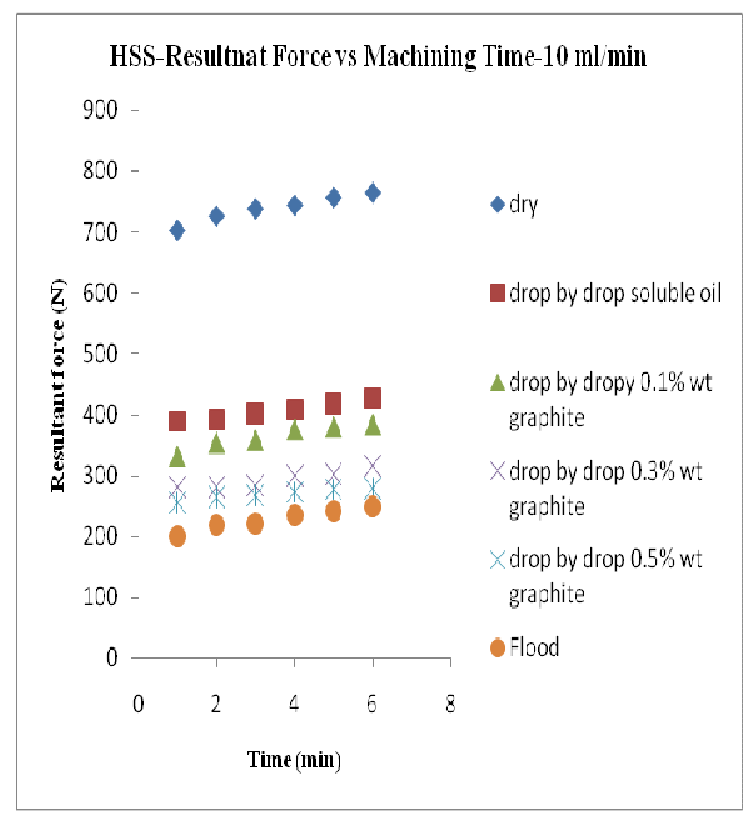

Fig. 5 Variation of resultant force with machining time when used HSS tool at $10 \mathrm{ml} / \mathrm{min}$

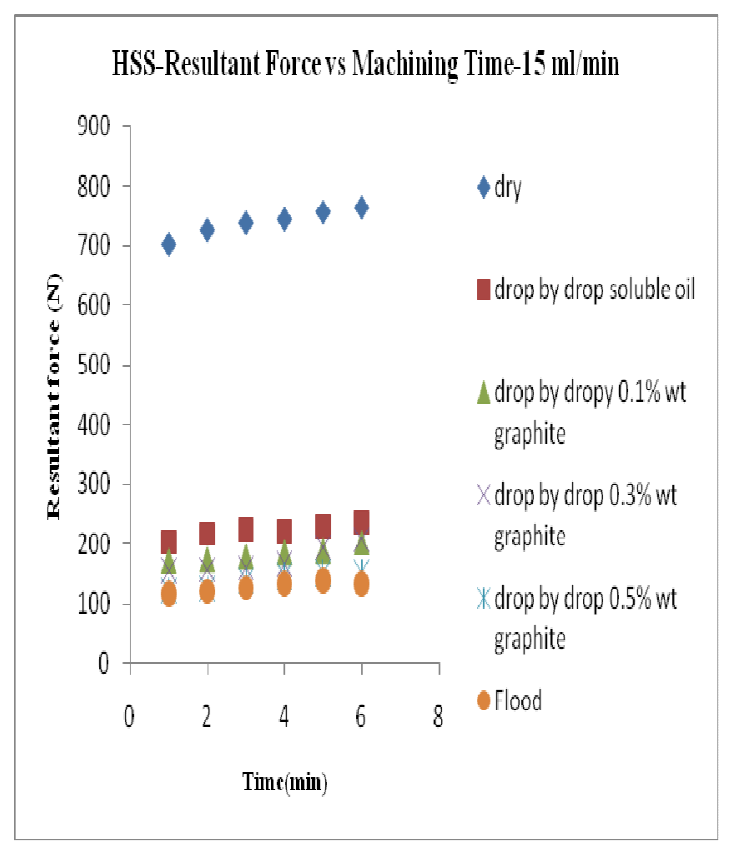

Fig.7 Variation of resultant force with machining time when used HSS tool at $15 \mathrm{ml} / \mathrm{min}$ 


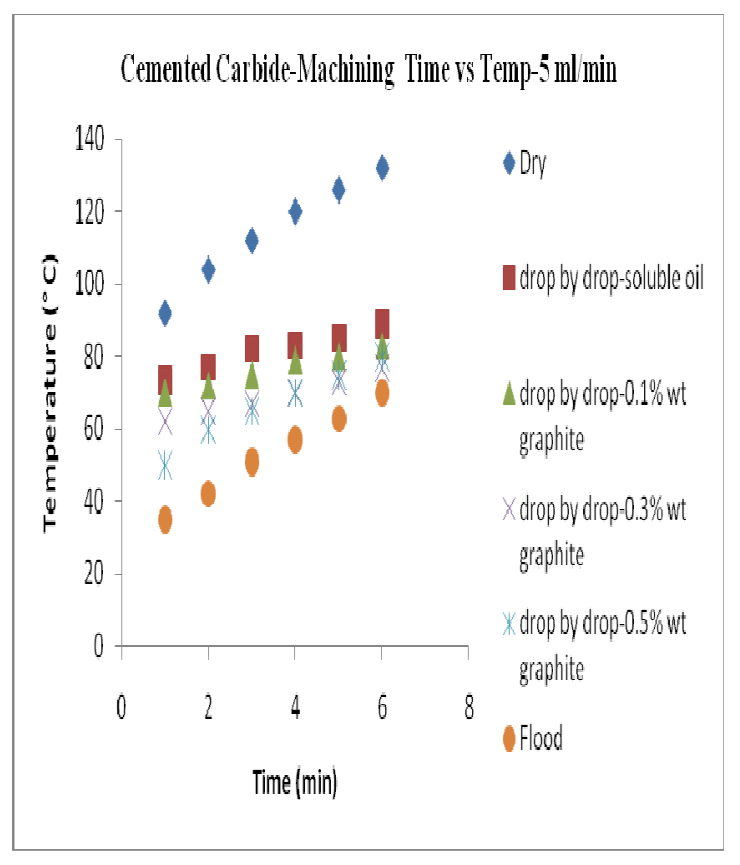

Fig.8 Variation of Temperature with machining time at different lubricating conditions when used Cemented Carbide tool at $5 \mathrm{ml} / \mathrm{min}$

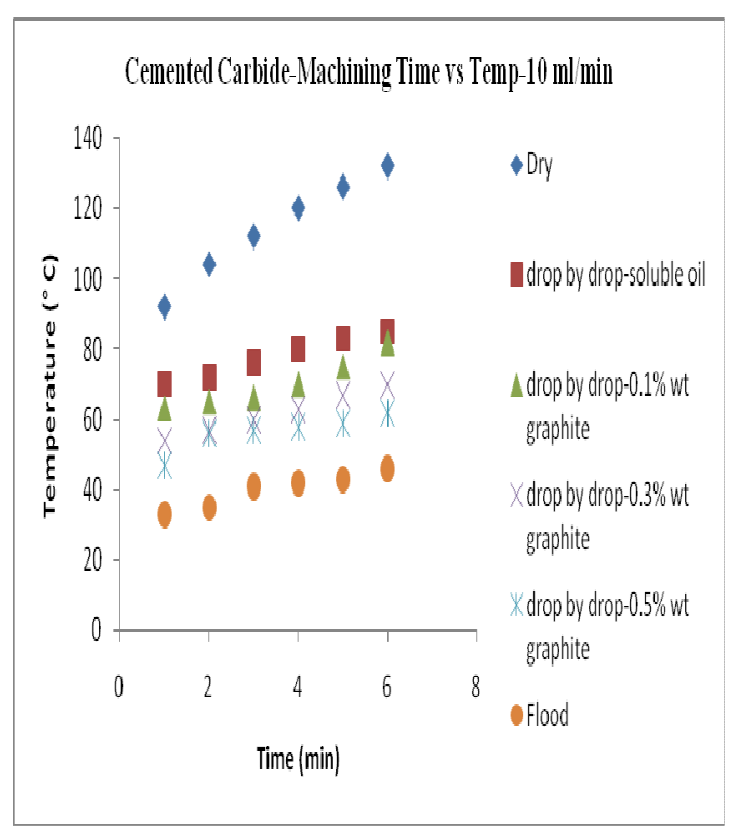

Fig.10 Variation of Temperature with machining time at different lubricating conditions when used Cemented Carbide tool at $10 \mathrm{ml} / \mathrm{min}$

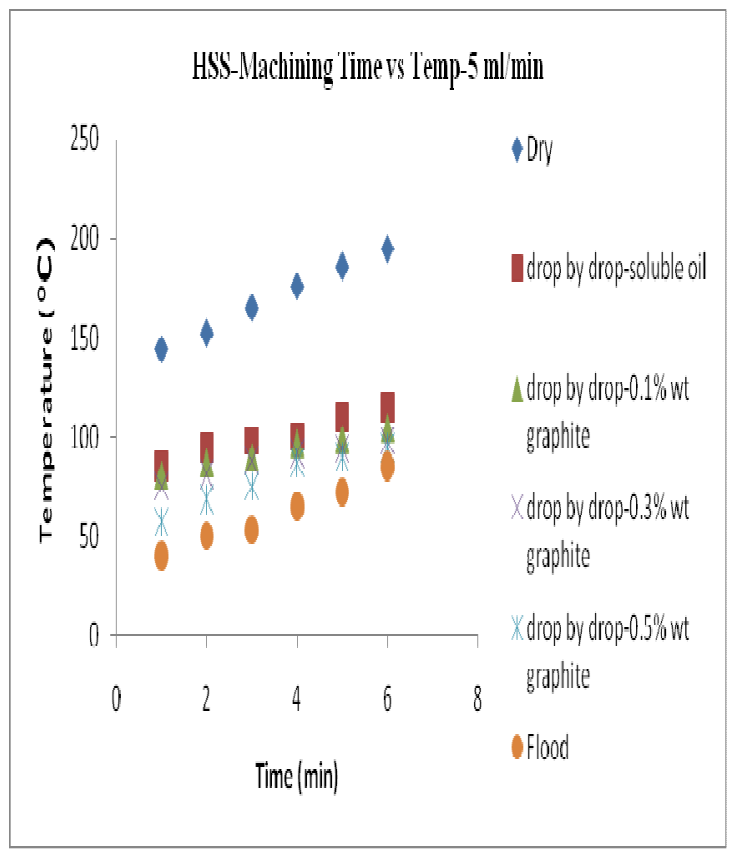

Fig.9 Variation of Temperature with machining time at different lubricating conditions when used HSS tool at $5 \mathrm{ml} / \mathrm{min}$

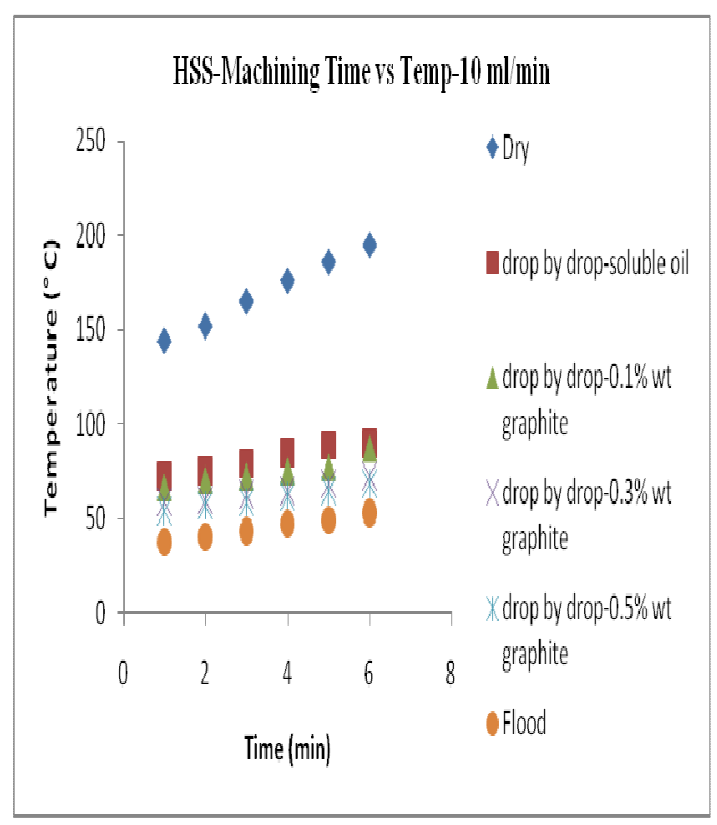

Fig.11 Variation of Temperature with machining time at different lubricating conditions when used HSS tool at $10 \mathrm{ml} / \mathrm{min}$ 


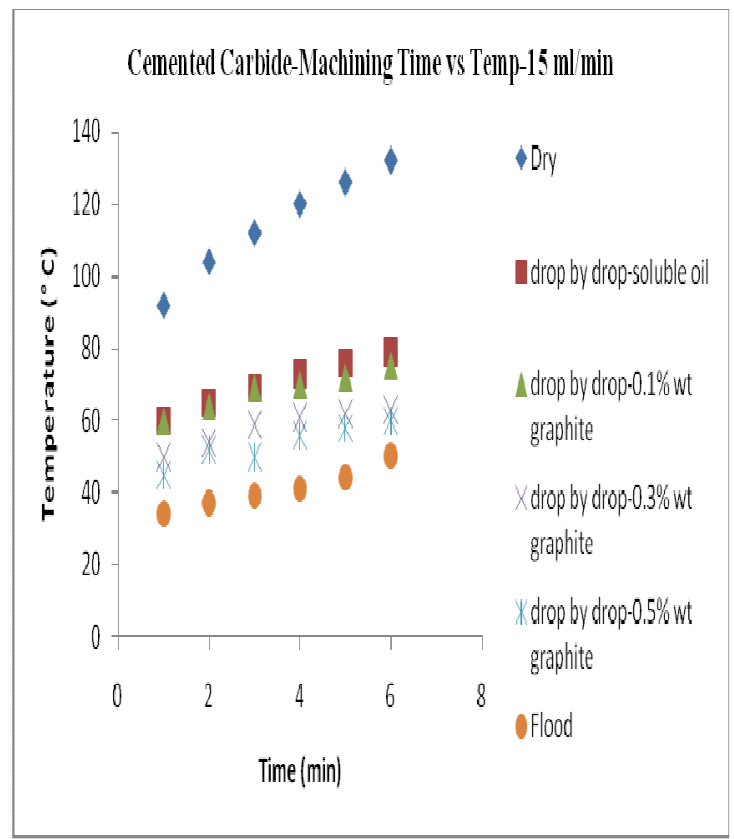

Fig.12 Variation of Temperature with machining time at different lubricating conditions when used Cemented Carbide tool at $15 \mathrm{ml} / \mathrm{min}$

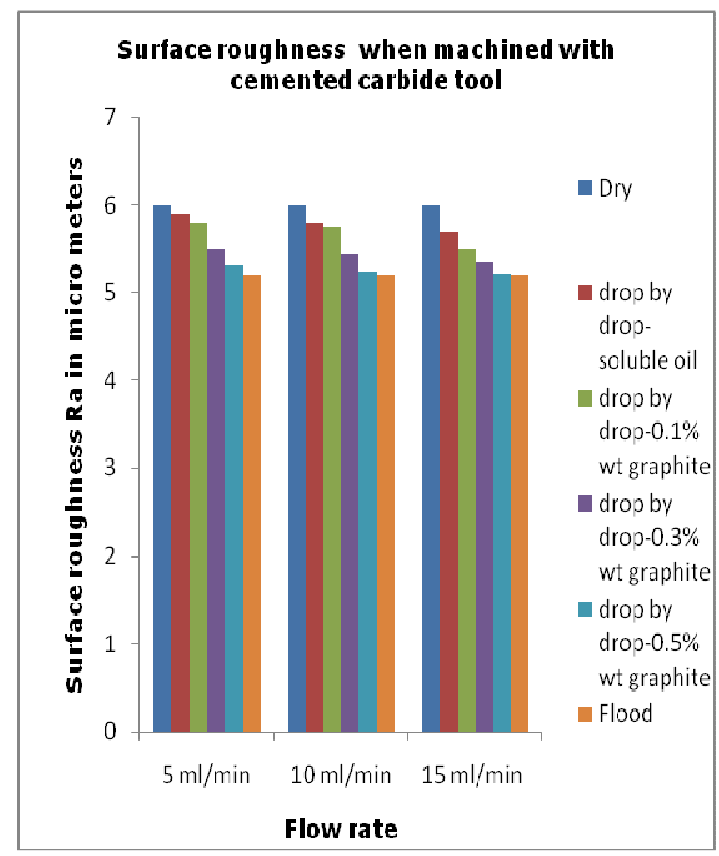

Fig.14 Variation of Surface Roughness at different flow rates \& lubricating conditions when machined with Cemented Carbide tool.

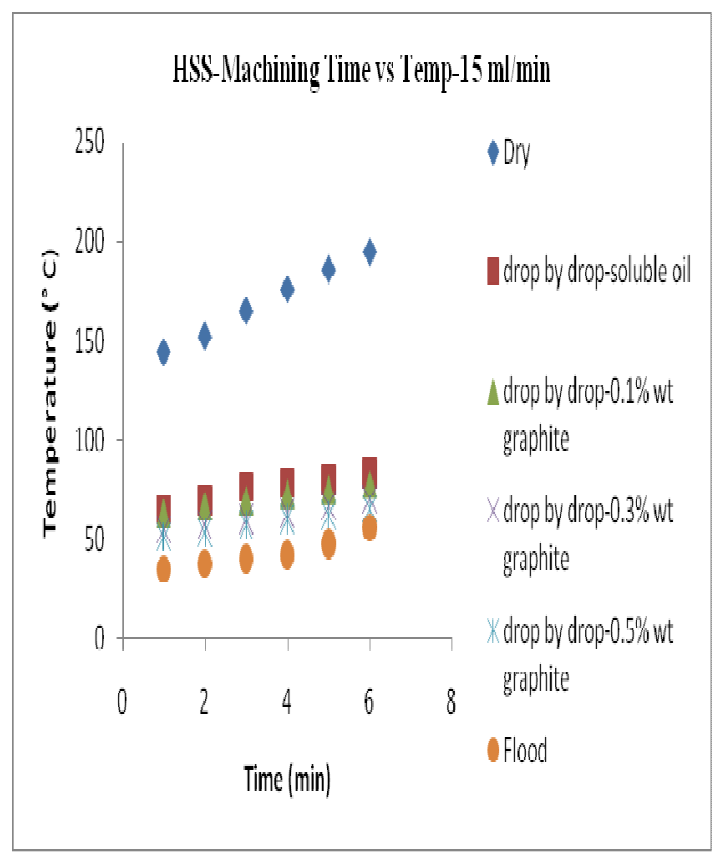

Fig.13 Variation of Temperature with machining time at different lubricating conditions when used HSS tool at $15 \mathrm{ml} / \mathrm{min}$

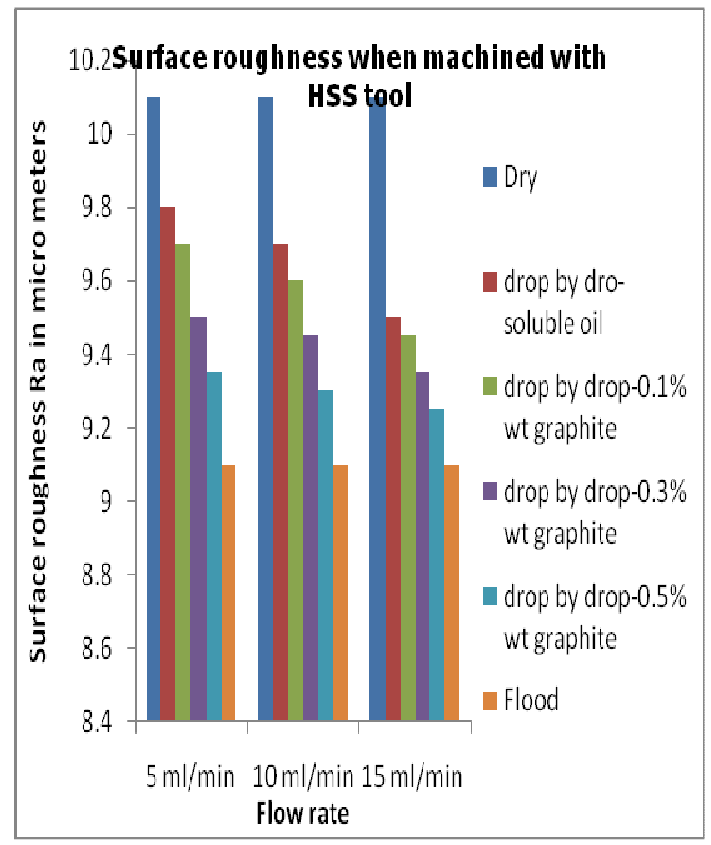

Fig.15 Variation of Surface roughness at different flow rates \& lubricating conditions when machined with HSS tool. 


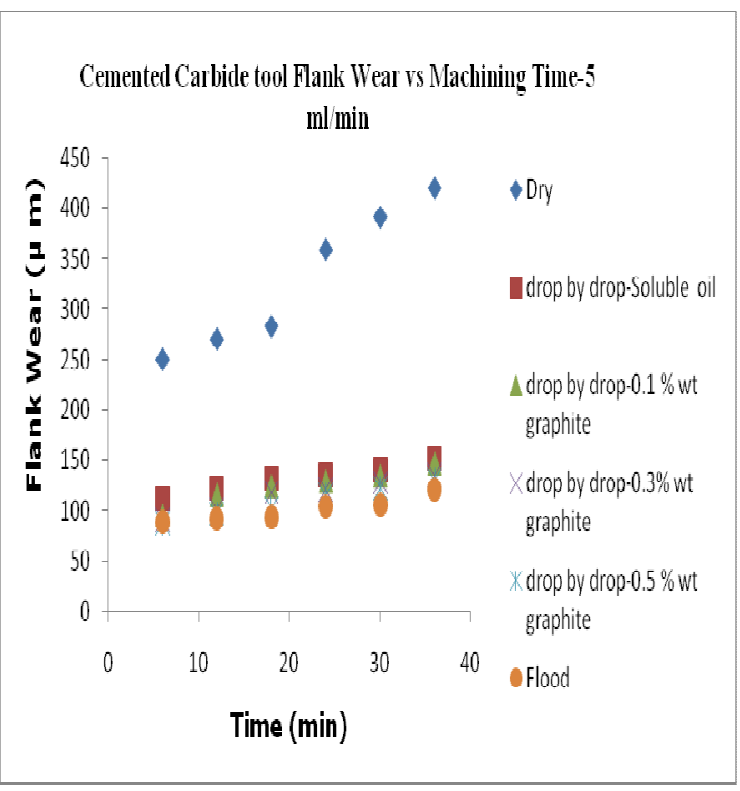

Fig 16 Variation of Flank wear with machining time at different lubricating conditions when used Cemented Carbide tool at $5 \mathrm{ml} / \mathrm{min}$

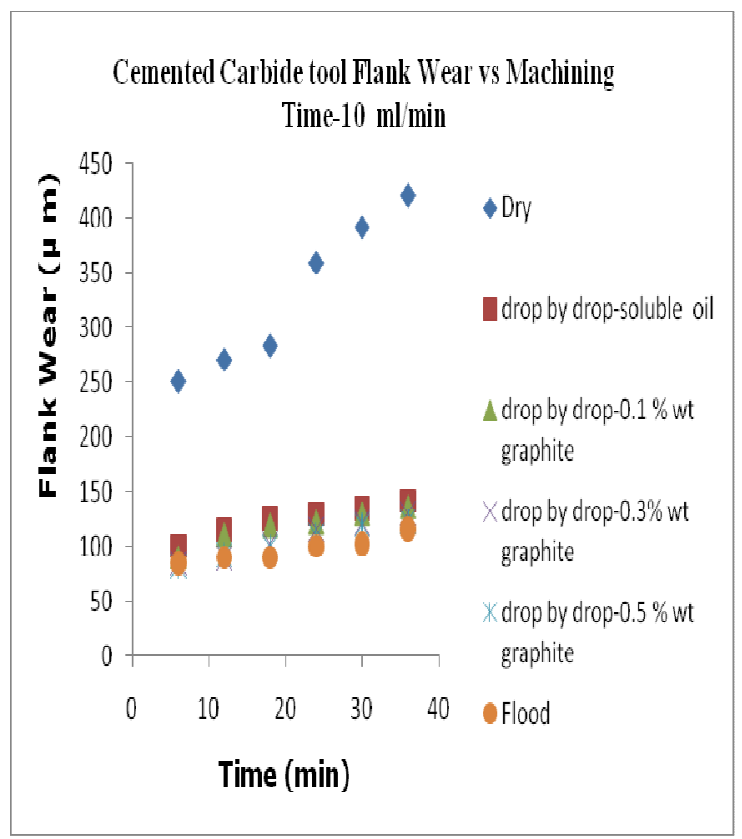

Fig 18 Variation of Flank wear with machining time at different lubricating conditions when used Cemented Carbide tool at $10 \mathrm{ml} / \mathrm{min}$

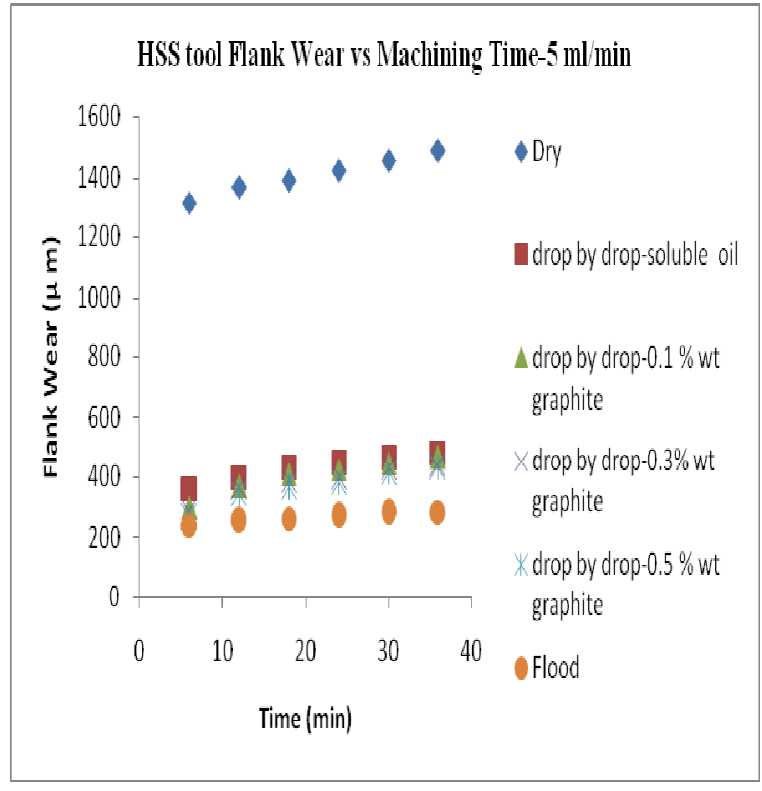

Fig.17 Variation of Flank wear with machining time at different lubricating conditions when used HSS tool at $5 \mathrm{ml} / \mathrm{min}$

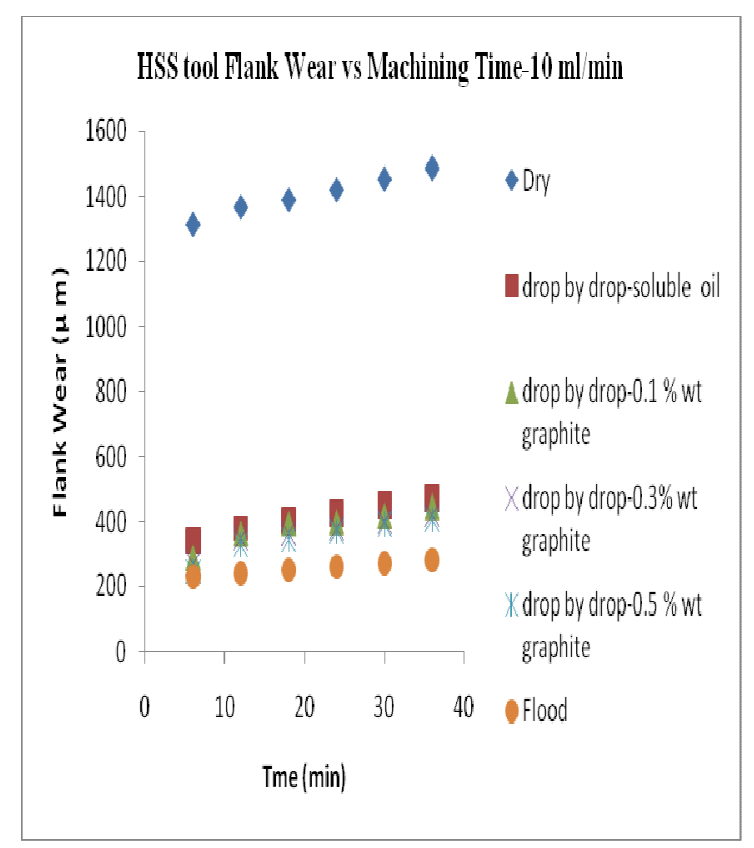

Fig.19 Variation of Flank wear with machining time at different lubricating conditions when used HSS tool at $10 \mathrm{ml} / \mathrm{min}$ 


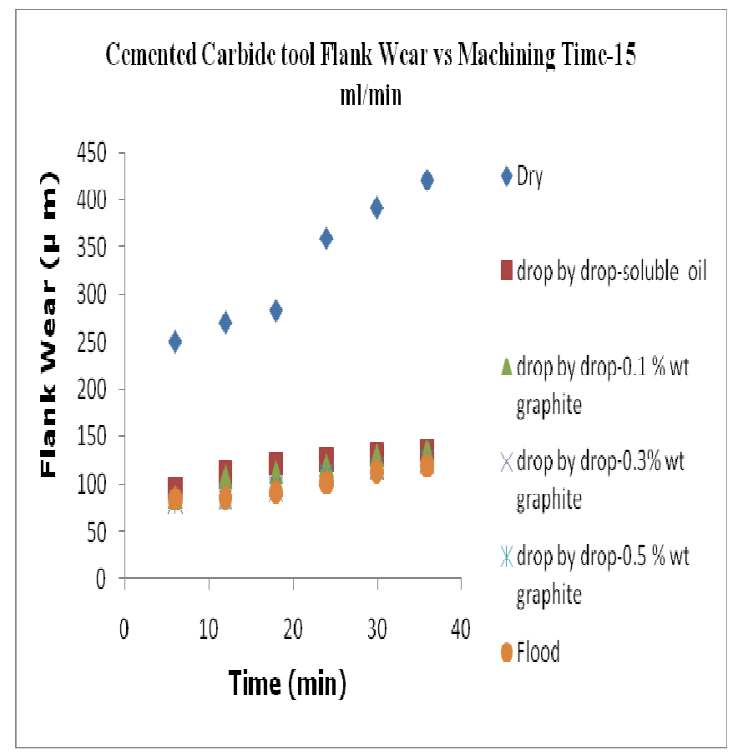

Fig 20 Variation of Flank wear with machining time at different lubricating conditions when used Cemented Carbide tool at $15 \mathrm{ml} / \mathrm{min}$

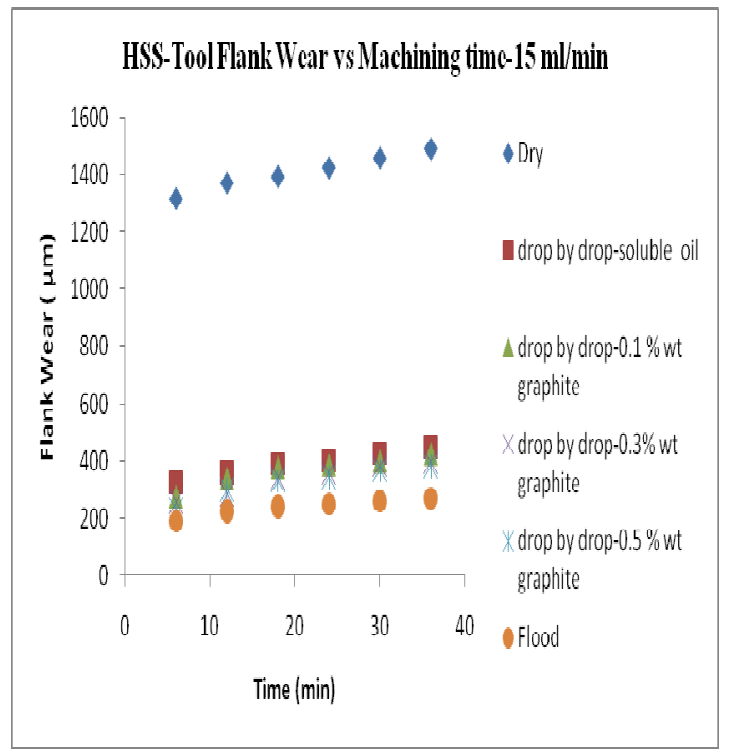

Fig.21 Variation of Flank wear with machining time at different lubricating conditions when used HSS tool at $15 \mathrm{ml} / \mathrm{min}$

\section{BIOGRAPHIES}

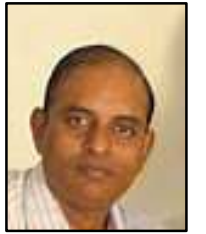

M M S Prasad is working as a Professor in dept of Mechanical engg having working experience of $17 \mathrm{yrs}$ industrial experience and 11 yrs teaching experience. Pursuing $\mathrm{Ph} D$ in GITAM University in manufacturing area under the guidance of Dr R R Srikanth. Other responsibilities like Nodal officer, ISO institutional coordinator, Infrastructure coordinator.

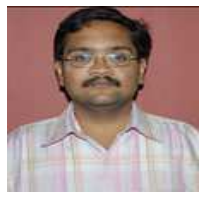

R.R.Srikant is working as a Associate Professor in dept of Mechanical engg in GIT, GITAM University who did his $\mathrm{Ph} \mathrm{D}$ in Andhra University, Visakhapatnam and having teaching experience of $13 \mathrm{yrs}$. 